\title{
Thermal curing and Degradation Behaviour of Silicon-containing Arylacetylene Resins
}

Kangkang Guo ${ }^{a b}$, Ping $\mathrm{Li}^{b}$, Yaping Zhu ${ }^{a}$, Fan Wang ${ }^{a}$, Huimin Qi ${ }^{a *}$ 


\section{$1 \quad$ Abstract}

2 Silicon-containing aryacetylene resins (PSAs) have already shown potential 3 application as heat-resistant materials due to their excellent thermal stability. The 4 formation and degradation of structures in cured PSAs are very important to evaluate 5 the thermal properties during their applications. Herein, the thermal curing and 6 degradation behavior of PSAs with different substituents were investigated by DSC, FT-IR, Py-GC-MS, TGA and TG-GC-MS. DSC and FT-IR analysis reveals that the curing reaction is dominated by the crosslinking reaction of $\mathrm{C} \equiv \mathrm{C}-\mathrm{H}$ and $\mathrm{Si}-\mathrm{C} \equiv \mathrm{C}-$, meanwhile, the reactive substituents (such as $\mathrm{Si}-\mathrm{H}$ and $\mathrm{Si}-\mathrm{CH}=\mathrm{CH}_{2}$ ) could promote the $\mathrm{C} \equiv \mathrm{C}-\mathrm{H}$ and $\mathrm{Si}-\mathrm{C} \equiv \mathrm{C}$ - reaction with higher conversion. Py-GC-MS was used to detect the pyrolysis products at $650^{\circ} \mathrm{C}$ and $750^{\circ} \mathrm{C}$, respectively, and the results could provide important information about the curing reaction and structures of cured PSAs. The curing reaction of PSAs mainly contains cyclotrimerization and Diels-Alder reaction of $\mathrm{C} \equiv \mathrm{C}-\mathrm{H}$ and $\mathrm{Si}-\mathrm{C} \equiv \mathrm{C}$-, and some addition reaction to form polyene structure. The main structures in cured PSAs contain a lot of phenyl rings, some aromatic fused rings and a little of polyene structure, moreover, their contents in cured PSAs are dependent on the substituents of the precursors. The TGA results show that the substituents of $\mathrm{Si}-\mathrm{H}$ and $\mathrm{Si}-\mathrm{CH}=\mathrm{CH}_{2}$ can effectively improve the crosslinking index of the cured PSA-H and PSA-V, and endow them with better thermal stability. Additionally, the degradation behavior of cured PSAs have been well studied by TG-GC-MS. When the temperature is $400^{\circ} \mathrm{C}$, the $\mathrm{Si}_{-} \mathrm{CH}_{3}$ and some aliphatic structure begin to degrade and form $\mathrm{CH}_{4}$, and with the temperature increasing to $500^{\circ} \mathrm{C}$, the unsaturated and aliphatic structures decompose into $\mathrm{C}_{2} \mathrm{H}_{4}$ and $\mathrm{C}_{2} \mathrm{H}_{6}$, and after $600^{\circ} \mathrm{C}$, the aromatic rings and fused rings in cured PSAs are dehydrogenated and release $\mathrm{H}_{2}$. In addition, the content of the degradation products and their forming temperature are also related with the substituents.

\section{Key words:}

Silicon, arylacetylene, cure, degradation 


\section{Introduction}

Silicon-containing polymers composed of $\left[-\mathrm{SiR}_{2}-\mathrm{C} \equiv \mathrm{C}-\mathrm{Ar}-\right]$ units have received considerable attention due to their thermally cured resins that possess excellent thermal stability, low dielectric constant and loss factor, and high temperature mechanical properties [1-4]. These polymers have already shown potential applications as ceramic precursors, heat-resistant materials and matrix of advanced composites in aerospace and astronautics [5-7]. Also, these resins thermally cure without the evolution of volatile byproducts, and will form three-dimensional network structures which could offer the cured resins with excellent thermal stability, solvent resistance, chemical stability, etc [4]. Kuroki and Itoh investigated the curing mechanism of poly[(phenylsilylene)ethynylene-1, 3-phenyleneethynylene] (called as MSP) containing Si-H by the FT-IR, solid-state NMR and computational chemistry. The results showed that the formed three-dimensional network structures contained naphthalene rings from Diels-Alder reaction between $\mathrm{Ph}-\mathrm{C} \equiv \mathrm{C}$ and $\mathrm{C} \equiv \mathrm{C}$, and styrene structure from hydrosilylation reaction between $\mathrm{Si}-\mathrm{H}$ and $\mathrm{Ph}-\mathrm{C} \equiv \mathrm{C}[8,9]$. Kimura et al. studied the thermal curing behavior of diethynylbenzene-silylene polymers containing vinyl groups by the solid-state NMR method. It was found that the formed three-dimensional network structures involved naphthalene rings from Diels-Alder reaction of alkynyl groups, and aliphatic structure from addition reaction of vinyl groups and $\mathrm{Ph}-\mathrm{C} \equiv \mathrm{C}[4]$. Zhang et al. investigated the cross-linking reaction of poly[dimethylsilylene ethynylene phenylene ethynylene] (abbreviated as DMSEPE) containing methyl group by Py-GC-MS. They found several structures in three-dimensional network structures, such as polyene structure from the radical polymerization of $\mathrm{C} \equiv \mathrm{C}$, phenyl rings structure from cyclotrimerization of $\mathrm{C} \equiv \mathrm{C}$ and naphthalene rings structure from Diels-Alder reaction between $\mathrm{Ph}-\mathrm{C} \equiv \mathrm{C}$ and $\mathrm{C} \equiv \mathrm{C}$ [7]. However, to our best knowledge, there are few reports on the detailed and dominated structures in cured resins, especially for the influence of substituents connected to silicon atoms on these three-dimensional network structures. Meanwhile, 
1 during the applications of cured resins, the service temperature is very high, which

2 indicate the three-dimensional network structures are exposed to high temperature

3 environment [10]. Therefore, it is necessary to systematically investigate the detailed

4 three-dimensional network structures with different substituents during the curing

5 reaction and thermal degradation behavior of these structures under high temperature.

6 Differential scanning calorimetric analyses (DSC) and Fourier transform infrared

7 (FT-IR) are effective techniques to analyze the curing mechanism, and important

8 structural information can be obtained by these methods [11, 12]. Recently, pyrolysis-gas chromatography-mass spectrometry (Py-GC-MS) has become a very important technique for the analysis of polymer structures [12-14]. Despite the complexity of pyrolysis process, a wealth of information about the polymer structures is present in the pyrolysis products $[15,16]$. Thermogravimetric analysis (TGA) is one of the most commonly used thermal analysis technique. It can provide quantitative results regarding the thermal properties [17]. Thermogravimetry-gas chromatography-mass spectrometry (TG-GC-MS) is commonly used to investigate the thermal behavior of polymers, which could reveal a much more complex degradation pathway of polymers $[18,19]$.

In this contribution, three kinds of silicon-containing arylacetylene resins (PSAs), poly[(methylvinylsilylene)ethynylene-1, 3-phenyleneethynylene] (PSA-V) , poly[(methylhydrosilylene)ethynylene-1, 3-phenyleneethynylene] (PSA-H), poly[(dimethylvinylsilylene)ethynylene-1, 3-phenyleneethynylene] (PSA-M) were chosen to be model polymers. The thermal curing behavior and structure of cured resins were systematically investigated by DSC, FT-IR and Py-GC-MS. TGA and TG-GC-MS were used to investigate the thermal stability and degradation pathway of the cured resins by analysis of the gases evolved during the degradation. Also, the substitute effects on the curing and degradation behavior will be discussed.

(1)

9
30 


\section{Experiment}

\section{1 materials}

Diethynylbenzene was supplied by Fine Chemical Institute of East China University of Science and Technology and distilled on a vacuum line before use. Dichloromethylsilane, dimethyldichlorosilane, dichloromethylvinylsilane, toluene, tetrahydrofuran (THF), ethyl bromide (EtBr), silica gel, and magnesium powder were purchased from Sinopharm Chemical Reagent Co. Ltd.

\subsection{Preparation and Curing of PSA-V, PSA-M and PSA-H}

PSA-V, PSA-M and PSA-H were prepared by the condensation reactions between diethynylbenzene Grignard reagents and dichlorosilane in tetrahydrofuran as solvent (Scheme 1) according to the reported method [20, 21]. The PSAs were thermally cured according to the following procedures: $170^{\circ} \mathrm{C}$ for $2 \mathrm{~h}, 210^{\circ} \mathrm{C}$ for $2 \mathrm{~h}$, $250^{\circ} \mathrm{C}$ for $2 \mathrm{~h}, 300^{\circ} \mathrm{C}$ for $2 \mathrm{~h}$, and $350^{\circ} \mathrm{C}$ for $4 \mathrm{~h}$.

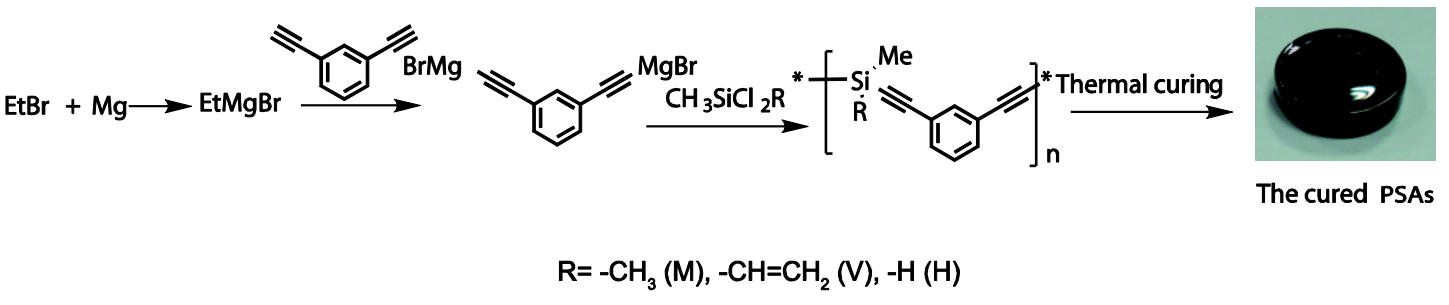
Scheme 1. Schematic illustration of the preparation and curing of silicon-containing arylacetylene resins (PSAs).

\subsection{Characterization}

Differential scanning calorimetric analyses (DSC) were performed on a NETZSCH $200 \mathrm{PC}$ module with a heating rate of $10^{\circ} \mathrm{C} / \mathrm{min}$ from ambient temperature to $300^{\circ} \mathrm{C}$ under nitrogen atmosphere. Fourier transform infrared (FT-IR) spectra were obtained using a Nicolet 550 spectrometer. The powder samples were previously milled and dried at $100^{\circ} \mathrm{C}$ for at least $2 \mathrm{~h}$. In order to analyze the absorption intensity changes of reactive groups in the FT-IR spectra, some absorptions were normalized and their relative conversions (a) at various curing temperatures were determined as follow [22]: 


$$
\mathrm{a}=1-\frac{\left(A_{i} / A_{r}\right)_{T}}{\left(A_{i} / A_{r}\right)_{T=25^{\circ} \mathrm{C}}}
$$

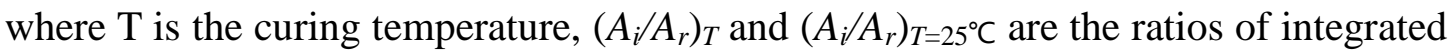
intensity of the specified band to the integrated intensity of the internal standard band at the curing temperature $\mathrm{T}$ and at the ambient temperature, respectively. The band of $\mathrm{Si}-\mathrm{CH}_{3}$ at $1255 \mathrm{~cm}^{-1}$ was used as an internal standard. The pyrolysis-gas chromatography-mass spectrometry (Py-GC-MS) analyses were conducted on a Frontier Lab Single-shot Pyrolyzer PY-2020i (PY Single-shot Pyrolyzer, quartz tube) and a Shimadzu GCMS-QP2010 chromatograph/mass spectrometer (Chromatographic column, $30 \mathrm{~m} \times 0.25 \mathrm{~mm}$ i.d. $\times 0.25 \mu \mathrm{m}$; carrier gas, helium gas; pressure, $34.0 \mathrm{kPa}$; total flow, $84.3 \mathrm{~mL} / \mathrm{min}$; column flow, $0.80 \mathrm{~mL} / \mathrm{min}$ ). Pyrolyses were carried out at $650^{\circ} \mathrm{C}$ and $750^{\circ} \mathrm{C}$, respectively. Thermogravimetric analyses (TGA) were performed on a TA Instruments SDT Q600 analyzer. All thermal analyses were conducted under nitrogen atmosphere at a heating rate of $10{ }^{\circ} \mathrm{C} / \mathrm{min}$ from ambient temperature up to $1000^{\circ} \mathrm{C}$. Evolved gas analyses were performed on a TG-GC-MS (INFICON Transpector 2) at a heating rate of $10^{\circ} \mathrm{C} / \mathrm{min}$ from ambient temperature up to $1000^{\circ} \mathrm{C}$ in a controlled dry helium flow of $50 \mathrm{~mL} / \mathrm{min}$. The evolved gases were analyzed by mass spectrometry on a Thermostar quadrupolar apparatus from Balzers instruments covering a mass range from 0 to $300 \mathrm{amu}$.

\section{Results and discussion}

\subsection{Thermal curing behavior}

The study of thermal curing behavior is important, which can reveal the heat-resistant structural information and its formation mechanism in cured PSAs. The type and composition of the pyrolysis products could give direct information about the structure of cured PSAs. Herein, DSC, FTIR and Py-GC-MS were used to investigate the thermal curing behavior of the three kinds of PSAs with different substituents, such as $\mathrm{Si}-\mathrm{H}$ for $\mathrm{PSA}-\mathrm{H}, \mathrm{Si}-\mathrm{CH}=\mathrm{CH}_{2}$ for $\mathrm{PSA}-\mathrm{V}, \mathrm{Si}-\mathrm{CH}_{3}$ for PSA-M. 


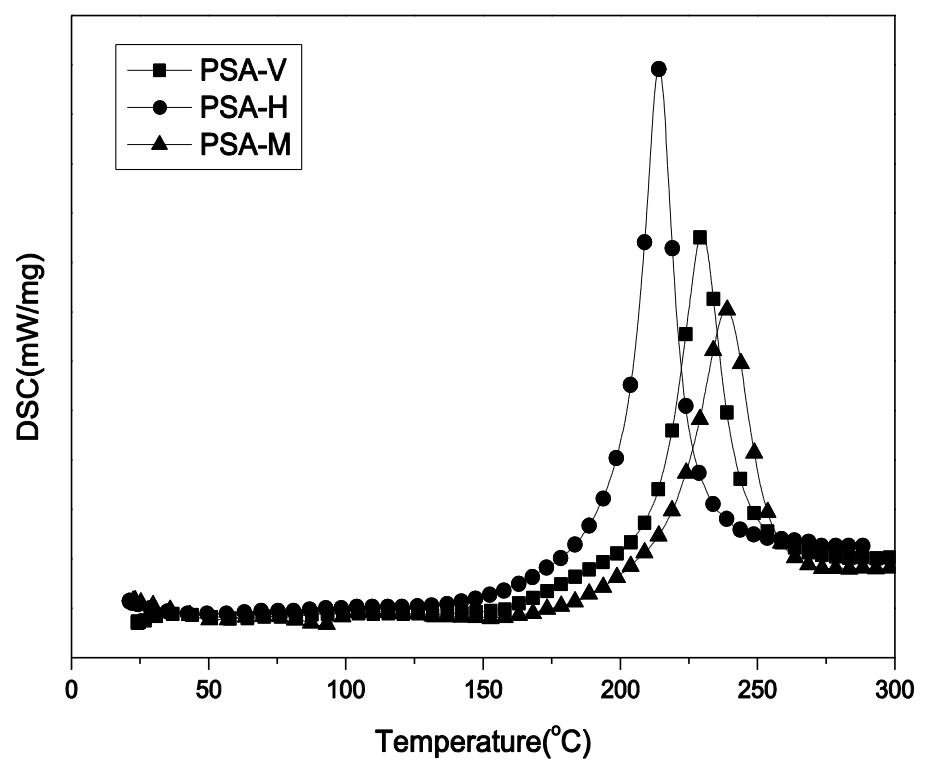

Figure 1. DSC thermogram $\left(10^{\circ} \mathrm{C} / \mathrm{min}\right.$ in $\left.\mathrm{N}_{2}\right)$ of cured PSAs.

Figure 1 shows the DSC thermogram of the thermal polymerization of PSAs with different substituent groups. A DSC thermogram of PSA-H exhibits an exotherm peaking at $214^{\circ} \mathrm{C}$, an initial curing temperature at $140{ }^{\circ} \mathrm{C}$ and a final temperature at $262^{\circ} \mathrm{C}$. A thermogram of PSA-V shows an exotherm peaking at $229^{\circ} \mathrm{C}$, an initial curing temperature at $160^{\circ} \mathrm{C}$ and a final temperature at $268^{\circ} \mathrm{C}$. However, for the PSA-M, an exotherm onset can be observed at about $170^{\circ} \mathrm{C}$, the $T_{\max }$ (the maximum of the curing exotherms) at $239^{\circ} \mathrm{C}$ and the final temperature at $273{ }^{\circ} \mathrm{C}$. These indicate that the substituent groups on silicon atom have a great influence on the curing reaction, which can be explained that the $\mathrm{Si}-\mathrm{H}$ and $\mathrm{Si}-\mathrm{CH}=\mathrm{CH}_{2}$ could be involved in the curing reaction, but the $\mathrm{Si}-\mathrm{CH}_{3}$ shows a certain inertness [3-5, 7]. Also, it can be seen that the curing reaction of PSA-H occur at lower temperature than those of the PSA-V and PSA-M, which is attributed to the higher activity of $\mathrm{Si}-\mathrm{H}$ than $\mathrm{Si}-\mathrm{CH}=\mathrm{CH}_{2}$ and $\mathrm{Si}-\mathrm{CH}_{3}$. Besides, the PSA-V exhibits higher reactivity than PSA-M due to the reactivity of $\mathrm{Si}-\mathrm{CH}=\mathrm{CH}_{2}$.

\subsubsection{FT-IR analysis}



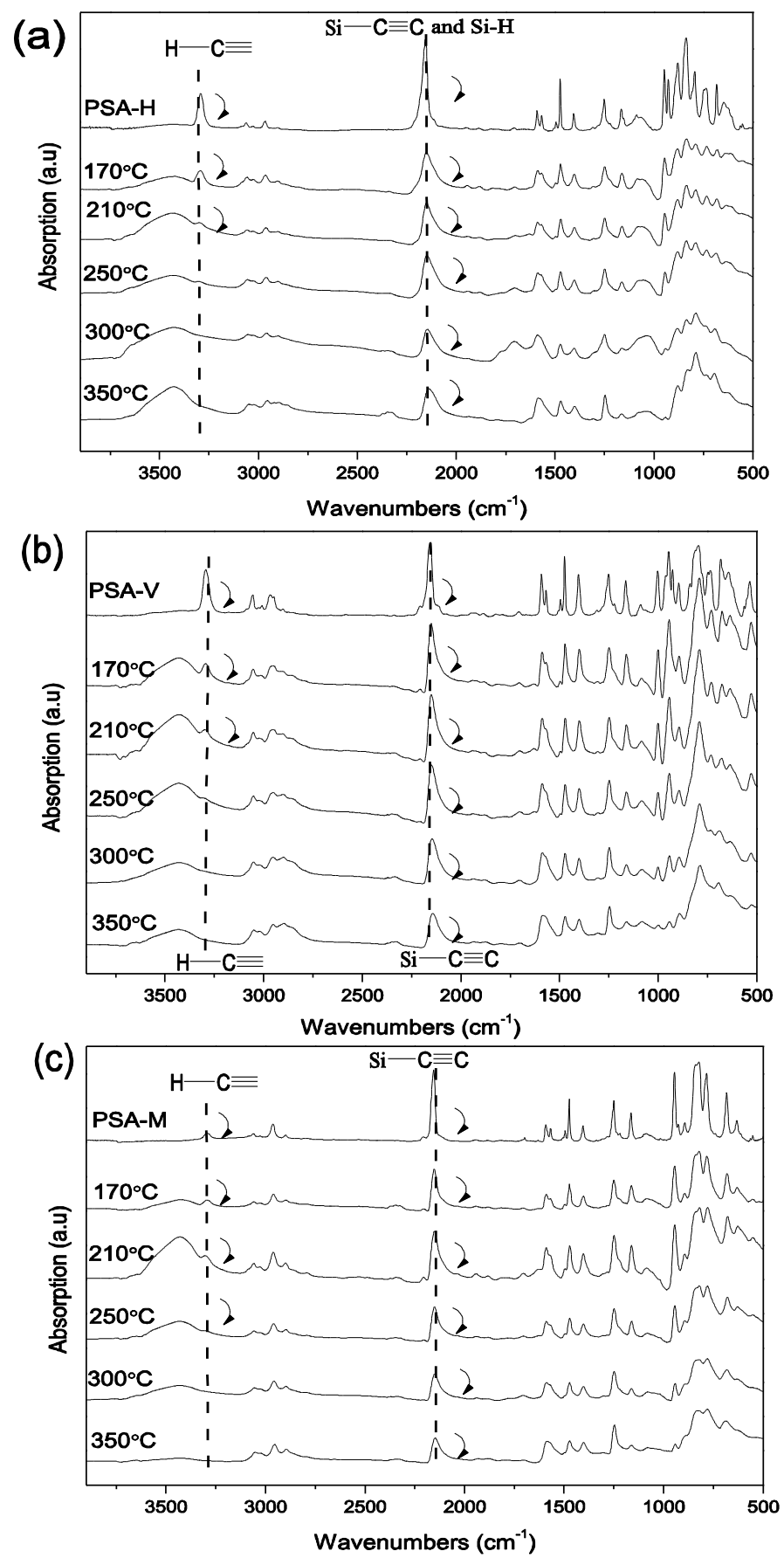

Figure 2. FT-IR spectra of PSAs after each cure cycle: (a) PSA-H, (b) PSA-V, (c) PSA-M.

2 FT-IR spectra of the PSAs at each curing cycle are shown in Figure 2. The 3 intensity of the absorption peaks at $3300 \mathrm{~cm}^{-1}$ and $2160 \mathrm{~cm}^{-1}$ assigned to $\mathrm{C} \equiv \mathrm{C}-\mathrm{H}$ and $4-\mathrm{C} \equiv \mathrm{C}-\mathrm{Si}(\mathrm{Me}) \mathrm{R}-(\mathrm{Si}-\mathrm{H}$ and $\mathrm{Si}-\mathrm{C} \equiv \mathrm{C}-$ in the same position for PSA-H) decreases 5 gradually with the curing temperature increasing. Meanwhile, the vinyl group $6 \quad\left(1404 \sim 1407 \mathrm{~cm}^{-1}\right)$ has the same tendency as Si-C $\equiv \mathrm{C}$ - for PSA-V. Additionally, the 7 absorption peaks of $\mathrm{Si}-\mathrm{C} \equiv \mathrm{C}$ - still can be seen after curing at $350^{\circ} \mathrm{C}$ for the cured 
1 PSAs, indicating that the curing reactions of PSAs are incomplete. Great changes can

2 be observed during the curing reaction for reactive groups (such as internal alkynes,

3 terminal alkynes, vinyl group and $\mathrm{Si}-\mathrm{H}$ ), which suggest that the curing reaction is

4 mainly the reaction of these reactive groups. However, the intensity of the absorption

5 peaks for $\mathrm{Si}-\mathrm{CH}_{3}$ in cured PSAs has no changes during the curing reaction, which can

6 be used as an internal standard to obtain the IR relative intensity of reactive groups for

7 measuring the conversion (a) of the reactive groups as equation (1) shown [2]. Thus,

8 the dependence of the conversion of the reactive groups with the curing temperature

9 are shown in Figure 3. It can be observed that the $\mathrm{C} \equiv \mathrm{C}-\mathrm{H}$ and $\mathrm{Si}-\mathrm{C} \equiv \mathrm{C}-$ of PSA-H

10 and PSA-V exhibit higher conversion than those of PSA-M. This can be explained

11 that the $\mathrm{Si}-\mathrm{H}$ and $\mathrm{Si}-\mathrm{CH}=\mathrm{CH}_{2}$ involve in the cross-linking reaction of $\mathrm{Si}-\mathrm{C} \equiv \mathrm{C}$ and $\mathrm{C}$

$12 \equiv \mathrm{C}-\mathrm{H}$, and increase their conversions, which could be confirmed by the lower curing temperature of PSA-H and PSA-V as shown in DSC thermogram. 

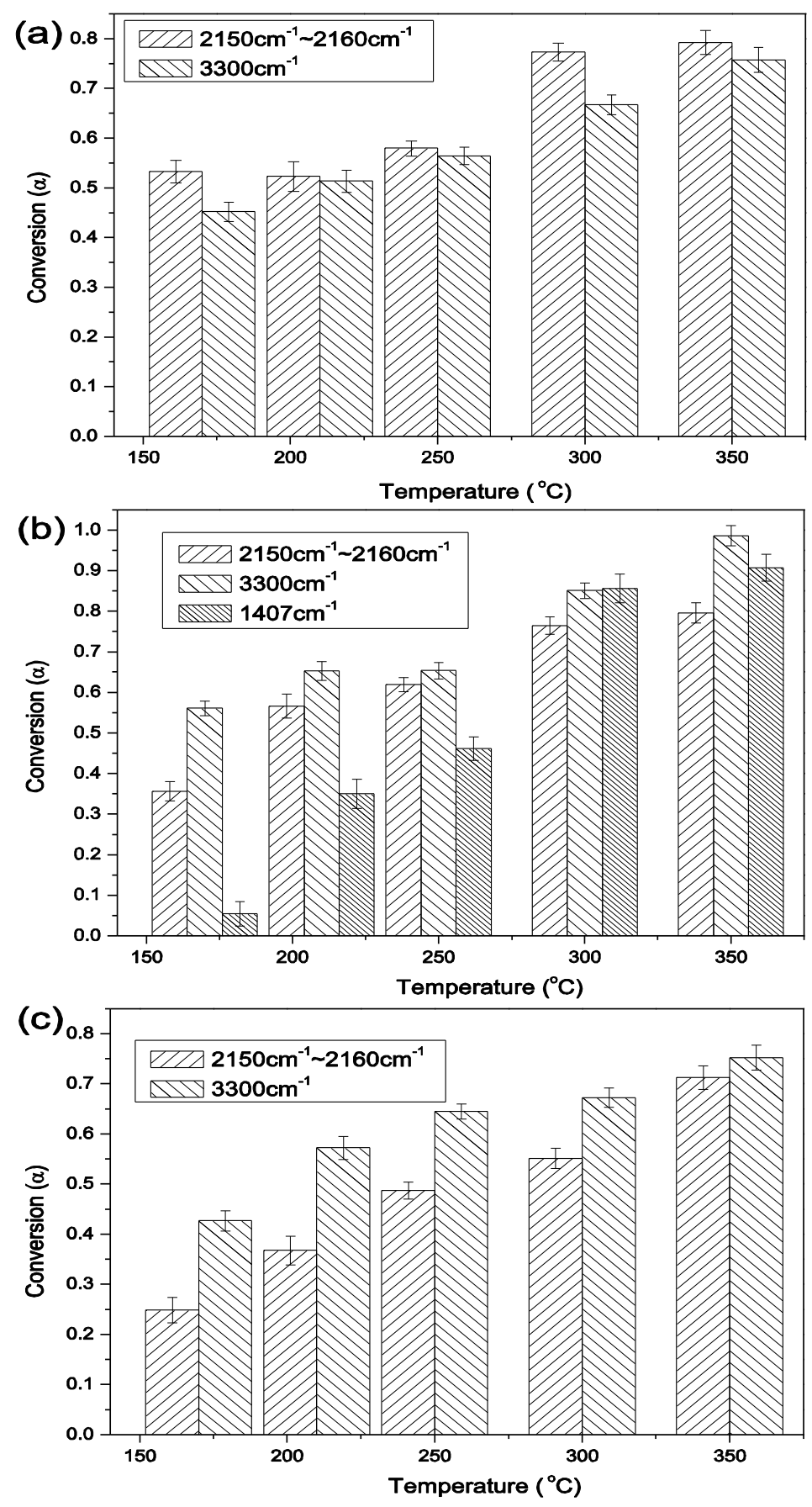

Figure 3. Conversion of reactive groups after each cure cycle for PSAs: (a) PSA-H, (b) PSA-V, (c) PSA-M.

Figure 3(c) shows that the conversion of $\mathrm{C} \equiv \mathrm{C}-\mathrm{H}$ is higher than $\mathrm{Si}-\mathrm{C} \equiv \mathrm{C}$ - for

3 the PSA-M at the same curing condition (time and temperature), which indicate the

4 terminal alkynes have higher reaction activity. Also, it can be observed that the

5 conversion of $\mathrm{C} \equiv \mathrm{C}-\mathrm{H}$ and $\mathrm{Si}-\mathrm{C} \equiv \mathrm{C}$ - for PSA-V is higher than those of PSA-M at the

6 same curing condition from Figure 3(b), which confirm the vinyl group involving the

7 curing reaction and improve the conversion. Figure 3(a) shows that the absorption 
1 bands at $2150-2160 \mathrm{~cm}^{-1}$ ( $\mathrm{Si}-\mathrm{H}$ and $\mathrm{Si}-\mathrm{C} \equiv \mathrm{C}$-) exhibit higher conversion than 3300

$2 \mathrm{~cm}^{-1}(\mathrm{C} \equiv \mathrm{C}-\mathrm{H})$ for PSA-H, which indicate the $\mathrm{Si}-\mathrm{H}$ involves in the curing reaction

3 and improve the conversion [8]. Besides, the $\mathrm{Si}-\mathrm{CH}=\mathrm{CH}_{2}$ exhibits lower conversion

4 than the $\mathrm{Si}-\mathrm{C} \equiv \mathrm{C}$ and $\mathrm{C} \equiv \mathrm{C}-\mathrm{H}$ at low curing temperature from the Figure 3(b), which

5 indicate that $\mathrm{Si}-\mathrm{CH}=\mathrm{CH}_{2}$ have lower reaction activity than $\mathrm{Si}-\mathrm{C} \equiv \mathrm{C}$ and $\mathrm{C} \equiv \mathrm{C}-\mathrm{H}$ at

6 this temperature [4].

7

\subsubsection{PY-GC-MS analysis}

Py-GC-MS is an effective method to investigate the possible structures of the different cured PSAs from the pyrolysis products. Figure 4 shows the GC spectra for pyrolysis products of the cured PSAs at $650^{\circ} \mathrm{C}$ and $750^{\circ} \mathrm{C}$ and the pyrolysis products

12 are summarized in Table 1.

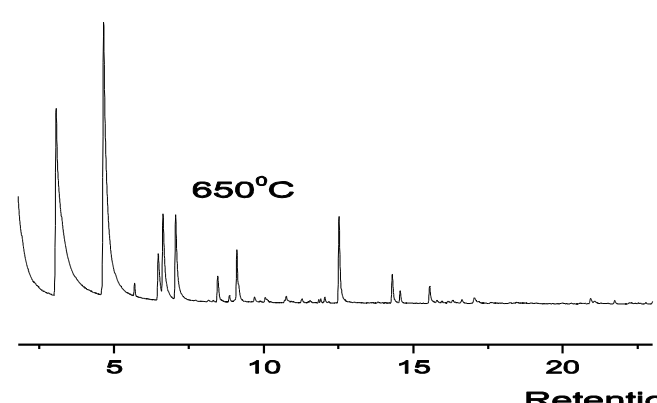

(a)
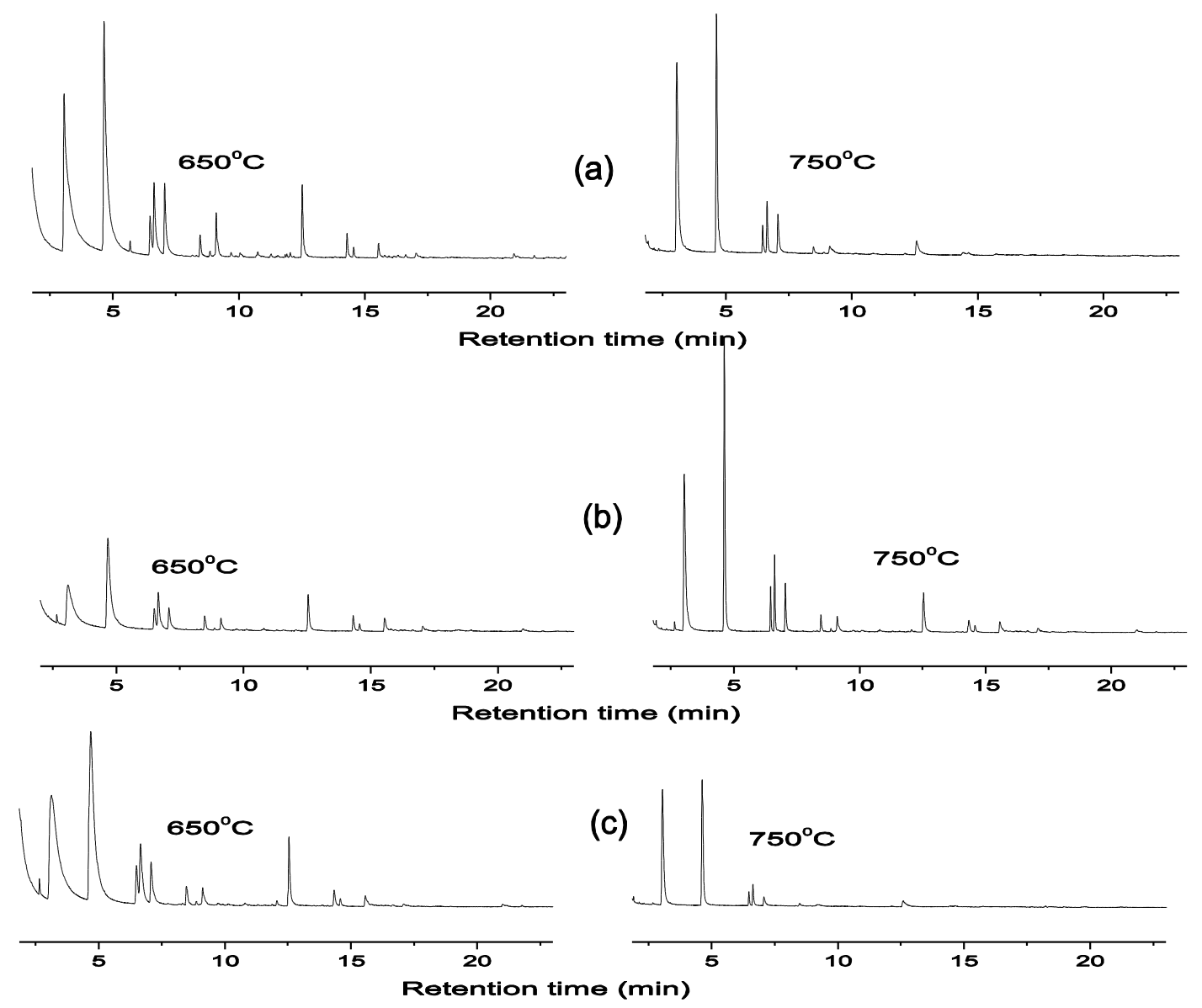

Figure 4. Py-GC-MS detection of gas products evolved from pyrolysis of cured PSAs: (a) PSA-H, (b) PSA-V, (c) PSA-M. 
Table 1. Percentage of pyrolysis products of cured PSAs.

\begin{tabular}{|c|c|c|c|c|c|c|c|c|}
\hline \multirow{3}{*}{$\begin{array}{l}\text { Retention } \\
\text { time (min) }\end{array}$} & \multirow{3}{*}{$\mathrm{M}_{\mathrm{W}}$} & \multirow{3}{*}{ Structure } & \multirow{2}{*}{\multicolumn{2}{|c|}{$\frac{\text { PSA-H }}{\text { Area (\%) }}$}} & \multirow{2}{*}{\multicolumn{2}{|c|}{$\begin{array}{c}\text { PSA-V } \\
\text { Area }(\%)\end{array}$}} & \multirow{2}{*}{\multicolumn{2}{|c|}{$\begin{array}{c}\text { PSA-M } \\
\text { Area (\%) }\end{array}$}} \\
\hline & & & & & & & & \\
\hline & & & $650^{\circ} \mathrm{C}$ & $750^{\circ} \mathrm{C}$ & $650^{\circ} \mathrm{C}$ & $750^{\circ} \mathrm{C}$ & $650^{\circ} \mathrm{C}$ & $750^{\circ} \mathrm{C}$ \\
\hline 1.92 & 68 & & & 0.22 & & 0.22 & & 0.51 \\
\hline 2.34 & 84 & & & 0.14 & & 0.14 & & 0.15 \\
\hline 3.07 & 78 & & 37.52 & 42.19 & 28.30 & 31.73 & 37.31 & 43.78 \\
\hline 4.65 & 92 & & 34.84 & 33.41 & 36.89 & 35.5 & 38.79 & 35.1 \\
\hline 6.47 & 106 & & 8.88 & 7.96 & 10.84 & 10.39 & 8.89 & 7.52 \\
\hline 7.06 & 104 & & 5.62 & 5.95 & 4.19 & 5.43 & 3.71 & 3.53 \\
\hline 8.47 & 120 & & 1.36 & 0.96 & 1.91 & 1.76 & 1.21 & 0.92 \\
\hline 12.53 & 128 & & 4.59 & 4.23 & 6.32 & 6.07 & 4.64 & 4.81 \\
\hline 14.31 & 142 & & 1.83 & 1.42 & 3.36 & 2.73 & 2.61 & 1.28 \\
\hline 15.56 & 154 & & 0.95 & 0.91 & 2.46 & 2.21 & 1.02 & \\
\hline 15.77 & 156 & & 0.19 & & 0.50 & 0.30 & 0.11 & \\
\hline 16.63 & 152 & & 0.16 & & 0.33 & 0.23 & 0.13 & \\
\hline 17.05 & 168 & & 0.34 & & 0.89 & 0.77 & 0.38 & \\
\hline 20.94 & 178 & & 0.30 & & 0.96 & 0.48 & 0.25 & \\
\hline
\end{tabular}

2

3 The identified products can be divided into three kinds: (1) olefin volatiles, i.e. 1,

4 4-pentadiene, cyclopentene and 1-hexene, (2) phenyl ring volatiles, i.e. benzene,

5 biphenyl, and their derivatives, and (3) aromatic fused ring volatiles, i.e. naphthalene,

6 phenanthrene, and their derivatives. The olefin volatiles only appear in the products at

$7 \quad 750^{\circ} \mathrm{C}$, and cannot be found in products at $650^{\circ} \mathrm{C}$. It can be proposed that the olefin

8 volatiles are from the further pyrolysis of aromatic rings at higher temperature.

9 Accordingly, the products at $650^{\circ} \mathrm{C}$ seem more effective to investigate the structure of 
1 the cured PSAs than those at $750^{\circ} \mathrm{C}$. The dominant products of cured PSAs are phenyl

2 ring volatiles, which are far higher than the aromatic fused ring volatiles. The phenyl

3 rings in products far exceed the phenyl ring in PSAs as designed in its synthesis

4 (Scheme 1), which indicates that some phenyl rings could be from the curing reaction

5 or cyclization during the pyrolysis [23]. Therefore, it is presumed that there are two

6 possible sources for the observed extra phenyl rings: (1) The phenyl rings are formed

7 by the cyclotrimerization (Scheme 2(a)) of C $\equiv$ C group during the thermal curing [24,

8 25], (2) polyene structure (Scheme 2(b)) obtained during curing reaction would

9 cyclize and produce the phenyl rings during the pyrolysis [11, 23]. The absorption

10 peaks of the polyene structure cannot be found from FT-IR spectra of cured PSAs

(Figure 2), but the signal of $\mathrm{CH}_{2}=\mathrm{CH}_{2}$ in the results of TG-GC-MS and styrene with content less than $6 \%$ in the Py-GC-MS products can be observed, which could indicate that the curing reaction contain a little of reaction as shown in Scheme 2(b). Therefore, it could be concluded that the phenyl rings in the products cured PSAs are mainly from the cyclotrimerization of $-\mathrm{C} \equiv \mathrm{C}$ - group during the thermal curing reaction of PSAs. The aromatic fused ring volatiles detected in products should be from the aromatic fused ring structure formed by Diels-Alder reaction (Scheme 2(c) and (d)) in cured PSAs [4, 7, 8, 11, 23]. Based on the analysis above, the main structure of the cured PSAs could be described as shown in Scheme 3. 

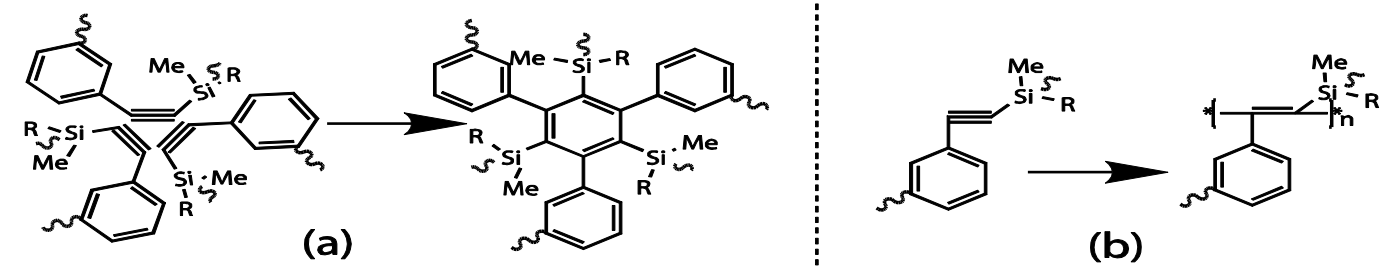

(b)
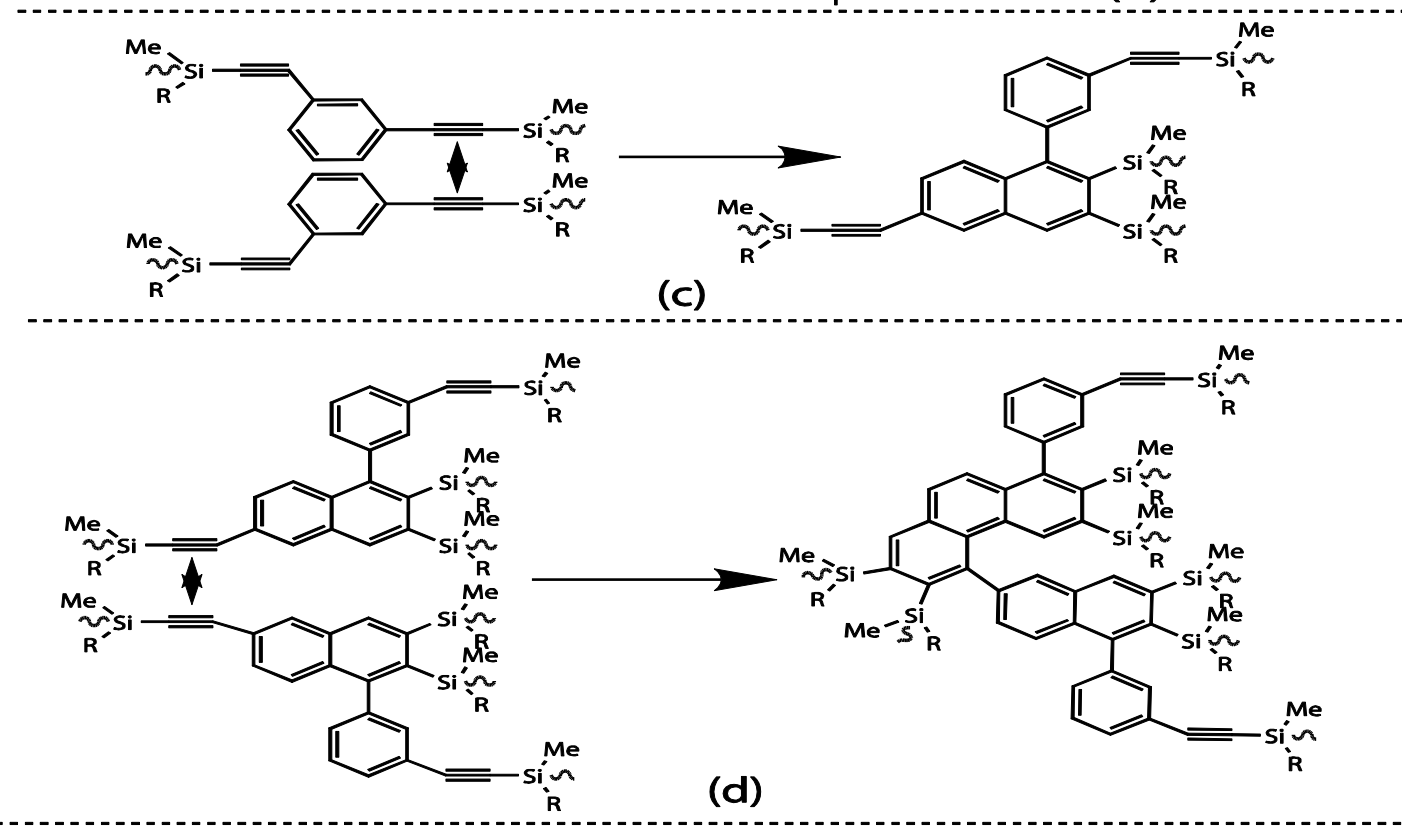

$\mathrm{R}=-\mathrm{CH}_{3},-\mathrm{CH}=\mathrm{CH}_{2},-\mathrm{H}$

Scheme 2. Schematic illustration of the thermal cure reaction of PSAs: (a) cyclitrimerization of $-C \equiv C$ - group, (b) addition reaction of $-\mathrm{C} \equiv \mathrm{C}$ - group, (c) Diels-Alder reaction of forming naphthalene ring, (d) Diels-Alder reaction of forming phenanthrene ring.

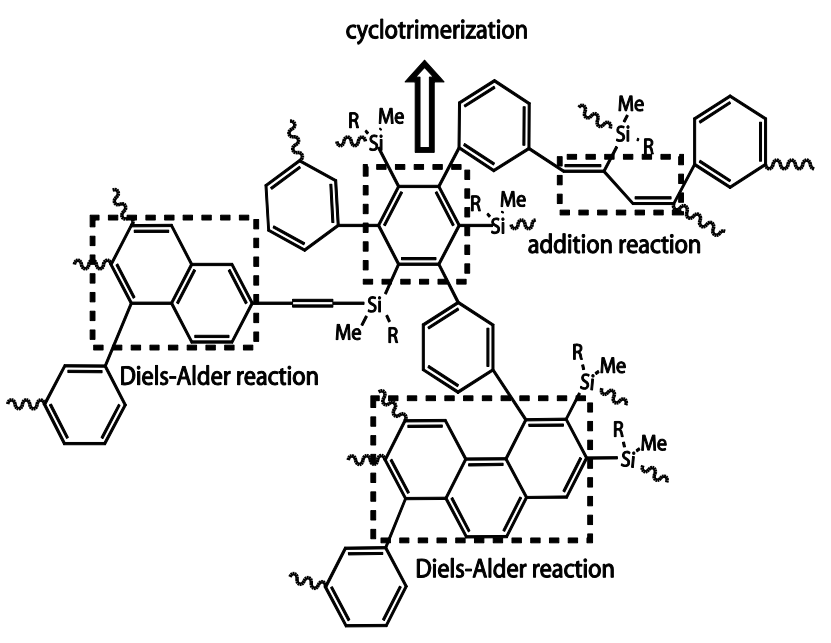

$\mathrm{R}=-\mathrm{CH}_{3},-\mathrm{CH}=\mathrm{CH}_{2},-\mathrm{H}$

Scheme 3. Schematic illustration of structures for cured PSAs. 
The relative contents of benzene in products of cured PSA-V $\left(28.30 \%\right.$ at $\left.650^{\circ} \mathrm{C}\right)$ are less than PSA-M $\left(37.31 \%\right.$ at $\left.650^{\circ} \mathrm{C}\right)$ and PSA-H $\left(37.52 \%\right.$ at $\left.650^{\circ} \mathrm{C}\right)$, but cured PSA-V has a highest content of the volatiles containing aromatic fused rings in three cured resins. This reveals the cured PSA-V containing more structure of aromatic fused rings. It is well known that the aromatic fused rings could be produced by Diels-Alder reaction, where phenyl rings are necessary in this reaction. The vinyl group in PSA-V is advantageous to rotation of molecule chains to form the syn-out conformation prone to Diels-Alder reaction [8]. However, this syn-out conformation is not easy to form in the curing process of the PSA-M, because the methyl group is shorter than the vinyl group, and not good for the motion of the molecular chains. Also, the molecular chains of PSA-H could be limited by the hydrosilation reaction of alkynyl groups at lower temperature as shown in Figure 2(a). Besides, Table 1 shows that the relative contents of styrene for cured PSA-V and PSA-H are higher than that of the cured PSA-M. This can be interpreted that the $\mathrm{Si}-\mathrm{H}$ and $\mathrm{Si}-\mathrm{CH}=\mathrm{CH}_{2}$ could react with alkynyl groups to form the structure containing styrene as shown in Scheme 4.<smiles>Cc1cccc(C=CNC(C)(C)C)c1</smiles>

(a)<smiles>Cc1cccc(/C(=C/CC[N+](C)(C)C)CC[Y](C)(C)C)c1</smiles>

(b)

Scheme 4. (a) Schematic illustration of addition reaction of $\mathrm{Si}-\mathrm{H}$ and $-\mathrm{C} \equiv \mathrm{C}-$ group, (b) Schematic illustration of addition reaction of $\mathrm{Si}-\mathrm{CH}=\mathrm{CH}_{2}$ and $-\mathrm{C} \equiv \mathrm{C}-$ group.

\subsection{Thermal degradation behavior}

The investigation of the thermal degradation behavior is very important to understand the thermal degradation mechanism and determine the limit of their service temperature. The thermal degradation behavior of cured PSAs is examined by TGA and TG-GC-MS from ambient temperature to $1000^{\circ} \mathrm{C}$. 


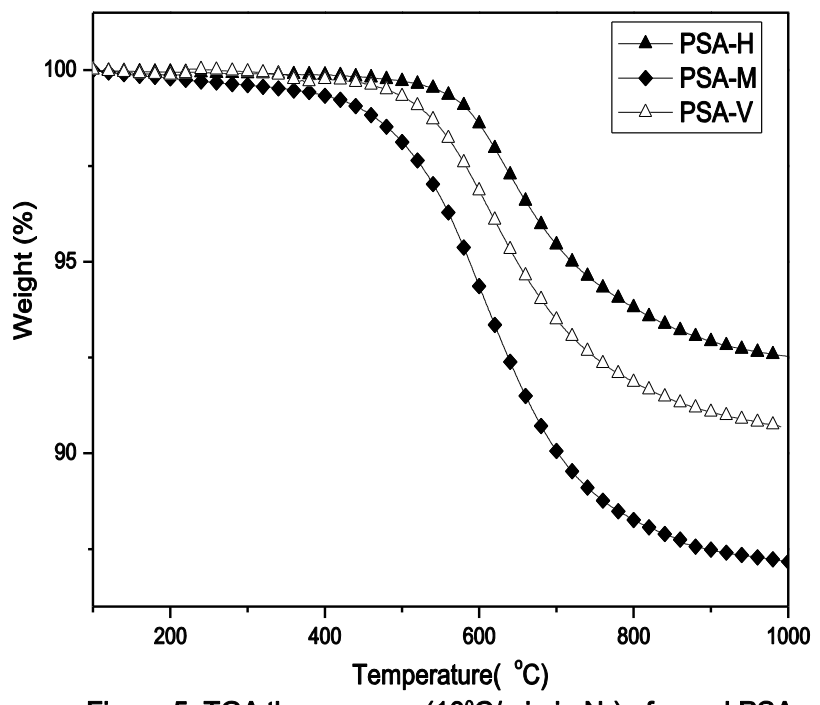

4

Table 2. Thermal property of the cured PSAs.

\begin{tabular}{lcc}
\hline & $T_{\mathrm{d} 5}\left({ }^{\circ} \mathrm{C}\right)$ & Residue $(\%)$ at $1000^{\circ} \mathrm{C}$ \\
\hline PSA-H & 715 & 93 \\
PSA-V & 650 & 91 \\
PSA-M & 583 & 87 \\
\hline
\end{tabular}

Figure 5. TGA thermogram $\left(10^{\circ} \mathrm{C} / \mathrm{min}\right.$ in $\left.\mathrm{N}_{2}\right)$ of cured PSAs. 
$1 \mathrm{Si}-\mathrm{H}$ and $\mathrm{Si}-\mathrm{CH}=\mathrm{CH}_{2}$ ) could improve their thermal stability. This can be explained

2 that $\mathrm{Si}-\mathrm{H}$ and $\mathrm{Si}-\mathrm{CH}=\mathrm{CH}_{2}$ involve in the curing reaction and improve the crosslinking

3 index of cured PSAs, which is also confirmed by the higher conversion of $\mathrm{C} \equiv \mathrm{C}-\mathrm{H}$

4 and $\mathrm{Si}-\mathrm{C} \equiv \mathrm{C}$ - for PSA-H and PSA-V from Figure 3a and 3b. Besides, it can be also

5 seen that PSA-H has a higher $T_{\mathrm{d} 5}$ and residual yield than PSA-V, which is attributed

6 to the difference in crosslinking reaction of $\mathrm{Si}-\mathrm{H}$ and $\mathrm{Si}-\mathrm{CH}=\mathrm{CH}_{2}$ as shown in

7 Scheme 4. It can be seen that the $\mathrm{Si}-\mathrm{CH}=\mathrm{CH}_{2}$ of PSA-V is prone to forming the

8 aliphatic chain, which is not stable during the process of thermal degradation.

9

10

11

3.2.2 TG-GC-MS analysis

12 

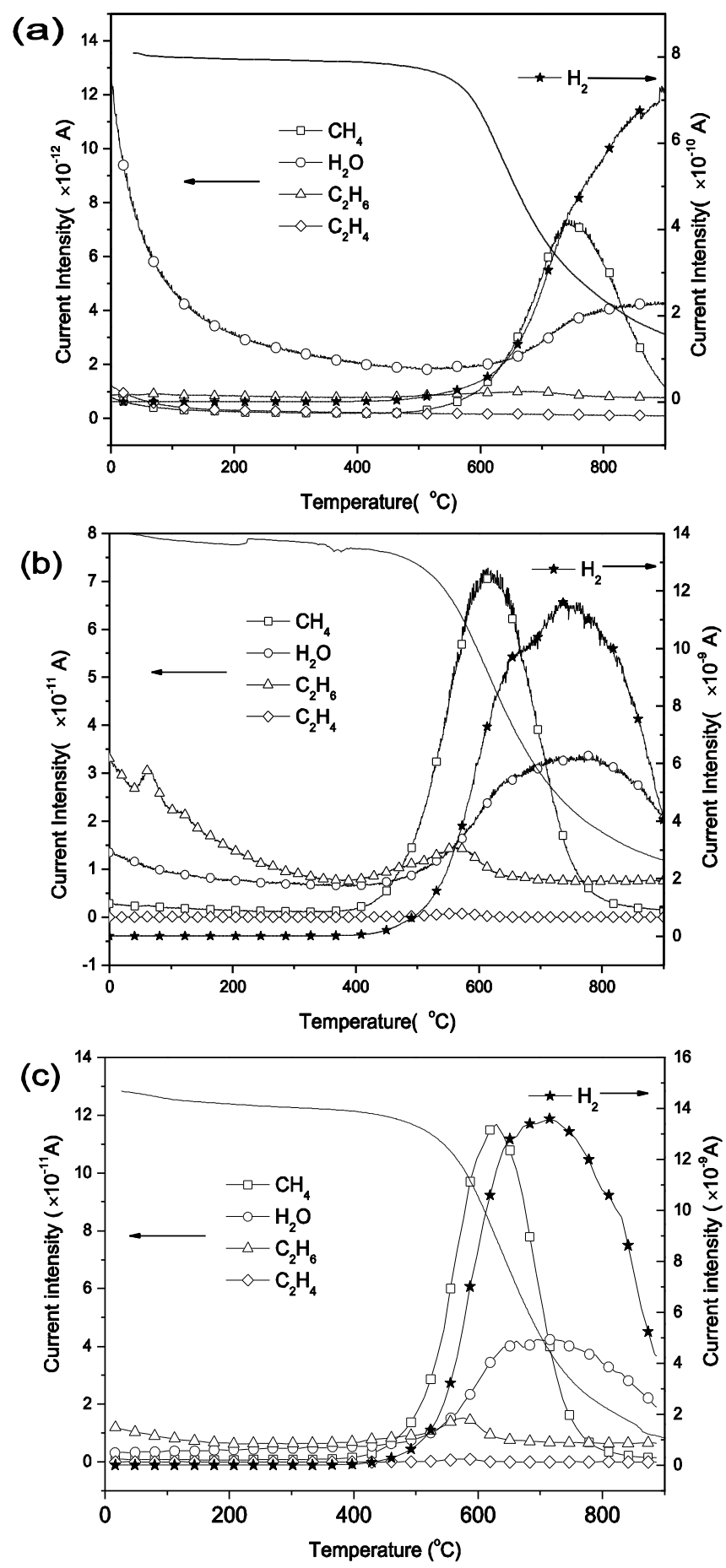

Figure 6. TG/GC/MS spectra of the gases evolved from cured

PSAs: (a) PSA-H, (b) PSA-V, (c) PSA-M. 


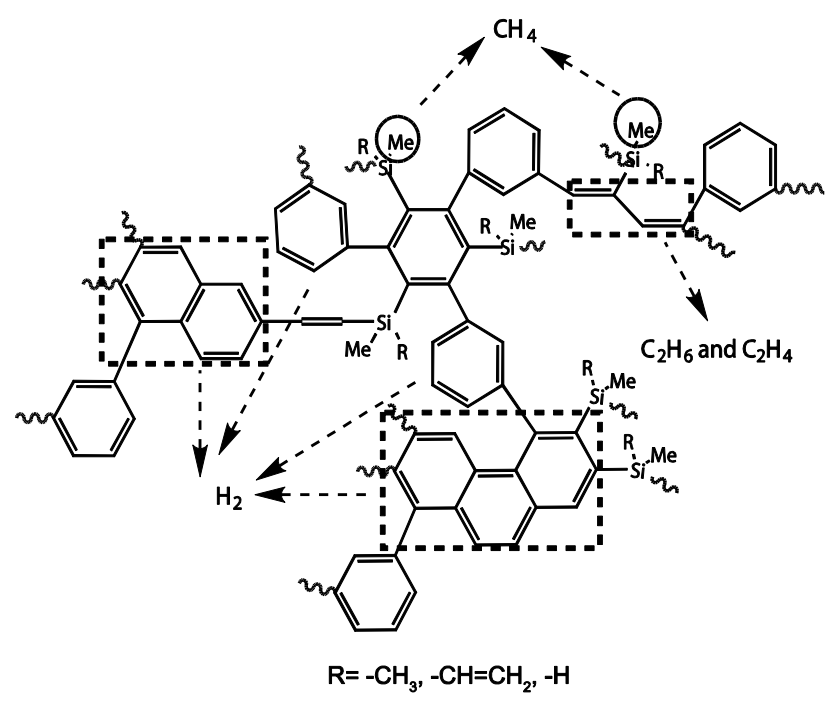

Scheme 5. Schematic illustration of thermal degradation of structures for cured PSAs.

The gas products from the thermal degradation process could further disclose the thermal degradation behavior. TG-GC-MS was used to analyze the evolved gas by a mass spectrometer. The results obtained at a heating rate of $10^{\circ} \mathrm{C} / \mathrm{min}$ were chosen to analyze all the possible degradation mechanisms. The evolved gases were analyzed as a function of the temperature as shown in Figure 6. The strong signals are observed from the $\mathrm{m} / \mathrm{z}$ fragments 2,16 and 18 corresponding to the $\mathrm{H}_{2}, \mathrm{CH}_{4}$ and $\mathrm{H}_{2} \mathrm{O}$, respectively. Besides, weak signals appear from the $\mathrm{m} / \mathrm{z}$ fragments 28 and 30 assigned to the $\mathrm{C}_{2} \mathrm{H}_{4} / \mathrm{CO}$ and $\mathrm{C}_{2} \mathrm{H}_{6}$. According to the analyses of fragments above, the structure of cured PSAs producing these ionic fragments is presumed as follow: (1) The methane from the elimination of $\mathrm{Si}-\mathrm{CH}_{3}$ and aliphatic structure, (2) The ethylene and ethane from the decomposition of unsaturated and aliphatic structure, (3) The hydrogen from the carbonization of aromatic rings and fused rings, (4) $\mathrm{H}_{2} \mathrm{O}$ from the product of reaction between hydrogen and oxygen used as an auxiliary gas. Therefore, the thermal degradation process for the structure of cured PSAs is concluded as Scheme 5 according to the Figure 6. When the temperature up to $400^{\circ} \mathrm{C}$, the $\mathrm{Si}-\mathrm{CH}_{3}$ and some aliphatic structure begin to degrade and form $\mathrm{CH}_{4}$. With the temperature increasing to $500^{\circ} \mathrm{C}$, the unsaturated and aliphatic structure decomposes into $\mathrm{C}_{2} \mathrm{H}_{4}$ and $\mathrm{C}_{2} \mathrm{H}_{6}$. After $600^{\circ} \mathrm{C}$, the aromatic rings and fused rings in cured PSAs are dehydrogenated and release $\mathrm{H}_{2}$. Meanwhile, the thermal degradation process is accompanied by $\mathrm{H}_{2} \mathrm{O}$ from the reaction between the $\mathrm{H}_{2}$ and $\mathrm{O}_{2}$ used as an auxiliary 
gas. Also, it can be clearly observed that the substituent groups have a great influence on the thermal degradation behavior from Figure 6. The initial formation temperature of $\mathrm{CH}_{4}$ and $\mathrm{H}_{2}$ for cured PSA-H is higher than cured PSA-V and PSA-M, which indicate the decomposition temperature of $\mathrm{Si}_{-}-\mathrm{CH}_{3}$ and the carbonization temperature of aromatic and fused rings for cured PSA-H is higher than cured PSA-V and PSA-M. This behavior is caused by the higher crosslinking index of cured PSA-H as discussed in TGA. In addition, the current intensity of $\mathrm{CH}_{4}$ for cured PSA-M is highest among three kinds of resins and the terminal temperature of $\mathrm{CH}_{4}$ is lowest, which can be interpreted that the cured PSA-M contains more $\mathrm{Si}-\mathrm{CH}_{3}$ prone to producing $\mathrm{CH}_{4}$ during thermal degradation. This indicate the cured PSA-M have lower thermal stability than PSA-V and PSA-H. Cured PSA-V and PSA-M exhibit more obvious current intensity of $\mathrm{C}_{2} \mathrm{H}_{4}$ and $\mathrm{C}_{2} \mathrm{H}_{6}$ than cured PSA-H. This can be explained that the cured PSA-M contain more unsaturated structures as shown in Figure 3(c), and the cured PSA-V contain the structure as shown in Scheme 4(b) which could decompose into $\mathrm{C}_{2} \mathrm{H}_{4}$ and $\mathrm{C}_{2} \mathrm{H}_{6}$. This confirm the highest thermal stability of cured PSA-H as discussed in TGA. Also, the current intensity of $\mathrm{m} / \mathrm{z}$ fragments for cured PSA-M is obviously higher than cured PSA-V except for $\mathrm{C}_{2} \mathrm{H}_{6}$ a little lower than cured PSA-V. This indicate the cured PSA-V have higher thermal stability than cured PSA-M, which has been confirmed by TGA.

\section{Conclusion}

The thermal curing and degradation behavior of PSAs with different substituents has been investigated, and the influence on the curing and degradation behavior from substituents has been discussed. DSC and FT-IR analysis shows that the curing reaction of PSAs is mainly the crosslinking reaction of $\mathrm{C} \equiv \mathrm{C}-\mathrm{H}$ and $\mathrm{Si}-\mathrm{C} \equiv \mathrm{C}$-. Meanwhile, the reactive substituents (such as $\mathrm{Si}-\mathrm{H}$ and $\mathrm{Si}-\mathrm{CH}=\mathrm{CH}_{2}$ ) could involve in the curing reaction and endow the $\mathrm{C} \equiv \mathrm{C}-\mathrm{H}$ and $\mathrm{Si}-\mathrm{C} \equiv \mathrm{C}$ - with higher conversions. Py-GC-MS results provide important information about the curing reaction and structure of cured PSAs. The curing reaction of PSAs is dominated by 
1 cyclotrimerization and Diels-Alder reaction, and also contains a little addition

2 reaction to form polyene structure. The main structures of cured PSAs contain phenyl

3 rings, aromatic fused rings and a little polyene structure, and their contents have some

4 dependence on the substituents. The TGA analysis shows that the reactive substituents

5 (such as $\mathrm{Si}-\mathrm{H}$ and $\mathrm{Si}-\mathrm{CH}=\mathrm{CH}_{2}$ ) could improve the crosslinking index of cured PSAs,

6 and endow cured PSA-H and PSA-V with better thermal stability than PSA-M.

7 TG-GC-MS is used to investigate the degradation process of cured PSAs, which

8 further give degradation behaviors of the structure of cured PSAs. When the

9 temperature up to $400^{\circ} \mathrm{C}$, the $\mathrm{Si}-\mathrm{CH}_{3}$ and some aliphatic structure begin to degrade

10 and form $\mathrm{CH}_{4}$, and with the temperature increasing to $500^{\circ} \mathrm{C}$, the unsaturated and

11 aliphatic structures decompose into $\mathrm{C}_{2} \mathrm{H}_{4}$ and $\mathrm{C}_{2} \mathrm{H}_{6}$, and after $600^{\circ} \mathrm{C}$, the aromatic

12 rings and fused rings in cured PSAs are dehydrogenated and release $\mathrm{H}_{2}$. Besides, the content of the degradation products and their forming temperature also are related with the substituents.

\section{Acknowledgement}

The authors gratefully acknowledge the support of the National Science Foundation of China (Grant No.90816021).

\section{References}

[1] M. Itoh, M. Mitsuzuka, K. Iwata, K. Inoue, A Novel Synthesis and Extremely High Thermal Stability of Poly[ (phenylsilylene)-ethynylene-1,3-phenyleneethynylenel, Macromolecules 27 (1994) 7917-7919.

[2] M. Itoh, K. Inoue, K. Iwata, M. Mitsuzuka, T. Kakigano, New Highly Heat-Resistant Polymers Containing Silicon: Poly(silyleneethynylenephenyleneethynylene)s, Macromolecules 30 (1997) 694-701. 
1 [3] B. Boury, J. P. Corriu, H. Muramatsu, Organisation and reactivity of silicon-based

2 hybrid materials with various cross-linking levels, New J. Chem. 26 (2002) 981 3988 .

4 [4] H. Kimura K. Okita, M. Ichitani, T. Sugimoto, S. Kuroki, I. Ando, Structural

5 Study of Silyl-Carborane Hybrid Diethynylbenzene-Silylene Polymers by

6 High-Resolution Solid-State ${ }^{11} \mathrm{~B},{ }^{13} \mathrm{C}$, and ${ }^{29} \mathrm{Si}$ NMR Spectroscopy, Chem. Mat. 15

7 (2003) 355-362.

8 [5] M. Narisawa, E. Tanaka, R. Nishimura, K. Okamura, M. Itoh, T. Kamiyama,

9 Synthesis and Characterization of Carbon-Base Hybrid Ceramics in Coating Form

10 from Thermosetting Resin - Alkoxide Mixtures, Key Eng. Mater. 2003, 247 (2003)

$11 \quad 137-140$.

[6] K. Inoue, K. Iwata, J. Ishikawa, S. Fujikake,; M. Itoh, Silicon-containing polymers for manufacture of ceramic moldings, Japanese patent JP 19970428 Japan (2003).

[7] J. Zhang, J. Huang, W. Du, F. Huang, L. Du, Thermal stability of the copolymers of silicon-containing arylacetylene resin and acetylene-functional benzoxazine, Polym. Degrad. Stab. 96 (2011) 2276-2283.

[8] S. Kuroki, K. Okita, T. Kakigano, J. Ishikawa, M. Itoh, Thermosetting Mechanism Study of Poly[(phenylsilylene)ethynylene-1,3-phenyleneethynylene] by Solid-State NMR Spectroscopy and Computational Chemistry, Macromolecules 31(1998) 2804-2808.

[9] S. Kuroki, T. Kakigano, J. Ishikawa, M. Itoh, K. Okita, Thermosetting mechanism of poly[(phenylsilylene)ethynylene-1,3-phenyleneethynylene], Köbunshi Rombun Shū 54 (1997) 229-235.

[10] Y. Yang, G. Xian, H. Li, L. Sui, Thermal aging of an anhydride-cured epoxy resin, Polym. Degrad. Stab. 118 (2015) 111-119.

[11] W.-C. Tseng, Y. Chen, G.-W. Chang. Curing conditions of polyarylacetylene prepolymers to obtain thermally resistant materials, Polym. Degrad. Stab. 94 (2009) 2149-2156. 
1 [12] K. R. Fontenot, M. M. Nguyen, M. Sameer, A.-A. Wahid, M. W. Easson, S.C.

2 Chang, G. A. Lorigan, B. D. Condon, The thermal degradation pathway studies of a

3 phpsphazene derivative on cotton fabric. Polym. Degrad. Stab. 120 (2015) 32-41.

4 [13] K. W. Sellers, C. M. Towns, C. R. Mubarak, L. Kloppenburg, U. H. F. Bunz, S.

5 L. Morgan, Characterization of high molecular weight poly(p-phenylenethynylene)s

6 by pyrolysis gas chromatography/mass spectrometry with multivariate data analysis, J.

$7 \quad$ Anal. Appl. Pyrol. 64 (2002) 313-326.

8 [14] T. Uenoa, E. Nakashima, K. Takeda, Quantitative analysis of random scission and chain-end scission in the thermal degradation of polyethylene, Polym. Degrad. Stab. 95 (2010) 1862-1869.

[15] T. Yamada, T. Okumoto, H. Ohtani, S. Tsuge, Characterization of epoxy resins cured with dicyandiamide in the presence of imidazole catalysts by high-resolution pyrolysis-gas chromatography, J. Anal. Appl. Pyrol. 33 (1995) 157-166.

[16] R. C. Galipo, W. J. Egan, J. F. Aust, M. L. Myrick, S. L. Morgan, Pyrolysis gas chromatography/mass spectrometry investigation of a thermally cured polymer, J. anal.Appl. Pyrol. 45(1998) 23-40.

[17] J. Fuente, M. Ruiz-Bermejo, C. Menor-Salván, S. Osuna-Esteban, Thermal characterization of HCN polymers by TG-MS, TG, DTA and DSC methods, Polym. Degrad. Stab. 96 (2011) 943-948.

[18] I. Hamerton, B. J. Howlin, P. Mhlanga, W. Aminah, W. Hassan, Using QSPR techniques to predict char yield arising from the thermal degradation of polybenzoxazines, Polym. Degrad. Stab. 98 (2013) 446-452.

[19] R. H. Aguirresarobe, L. Irusta, M. J. Fernandez-Berridi, Application of TGA/FTIR to the study of the thermal degradation mechanism of silanized poly(ether-urethanes), Polym. Degrad. Stab. 97 (2012) 1671-1679.

[20] M. Xu, S. Shi, Y. Wang, L. Zhang, Thermal pyrolytic behavior and kinetics of silicon-containing arylacetylene resin, Fiber Reinforced Plastics/Composites 6 (2010) 35-39. 
1 [21] F. Gao, L. Zhang, Y. Zhou, F. Huang L. Du, Synthesis and Characterization of

2 Poly[(methylsilyleneethynylenephenyleneethynylene)s-co-decamethylpentasiloxane],

$3 \quad$ J. Macromol. Sci. A 47 (2010) 861-866.

4 [22] Y. Liu, Z. Yue, J. Gao, Synthesis, characterization, and thermally activated

5 polymerization behavior of bisphenol-S/aniline based benzoxazine, Polymer 51 (2010)

$6 \quad 3722-3729$.

7 [23] C. Berrueco, J. Ceamanos, E. Esperanza, J. F. Mastral, Experimental study of

8 co-pyrolysis of polyethylene/sawdust mixtures, Thermal Science 8 (2004) 65-80.

9 [24] H. Fan, X. Li, Y. Liu, R. Yang, Thermal curing and degradation mechanism of 10 polyhedral oligomeric octa(propargylaminophenyl)silsesquioxane, Polym. Degrad. 11 Stab. 98 (2013) 281-287.

12 [25] M. Chen, C. Liu, J. Lin, Correlation of cross-linked structures and properties in 13 the characterization of dimethyl-diphenylethynyl-silane using DSC, TGA and 14 Py-GC/MS analysis, Polym. Degrad. Stab. 112 (2015) 35-42. 